\title{
PENGARUH KOMPETENSI TERHADAP KINERJA PEGAWAI PADA BIRO PEMBINAAN OPERASI MABES POLRI JAKARTA
}

\author{
Tri Ratnaningsih", Ana Septia Rahman² \\ Fakultas Ekonomi, Universitas Pamulang \\ Email: dosen01709@unpam.ac.id
}

\begin{abstract}
Purpose. The purpose of this study was to determine how much influence competence has on employee performance at the Police Headquarters Operations Development Bureau.

Method. This research method uses quantitative descriptive method with the population in this study as many as 48 employees at the Police Headquarters Operations Development Bureau. The sample research method is saturated sample where all the population is used as a sample, the method of analysis in processing this research data uses descriptive analysis method, Pearson product moment correlation test, coefficient of determination and hypothesis testing (test).

Result. The results of this study indicate that there is a significant influence between Competence on Employee Performance with a regression value of $Y=17.85+0.685 X$ which means that if each additional 1 (one) point of the competency variable then it will increase the performance by 0.607 times at a constant rate. amounting to 17.85. The correlation coefficient value of 0.7402 means that the competency variable has a strong level of relationship to the performance variable. From the calculation of the coefficient of determination (KD), it is obtained at 0.5479, it can be concluded that competence contributes to employee performance by $54.79 \%$ while the remaining $45.21 \%$ is influenced by other factors not examined. Hypothesis testing using the t-count statistical test obtained tcount $\geq$ ttable or 7.461> 2.013, which means that Ha is accepted and Ho is rejected, meaning that there is a significant relationship between competence and employee performance at the Jakarta Police Headquarters Operations Development Bureau.
\end{abstract}

Implications. The Police Headquarters Operations Bureau must regularly conduct training for all employees in accordance with management standards so that employees can complete tasks quickly and accurately, and always be consistent in giving employees time to complete tasks in order to achieve the work result targets that have been set effectively and efficient.

Keywords: Competence and Performance

\begin{abstract}
ABSTRAK
Tujuan. Tujuan penelitian ini adalah untuk mengetahui seberapa besar pengaruh kompetensi terhadap kinerja pegawai pada Biro Pengembangan Operasi Mabes Polri.

Metode. Metode penelitian ini menggunakan metode deskriptif kuantitatif dengan populasi dalam penelitian ini sebanyak 48 pegawai pada Biro Pengembangan Operasi Mabes Polri. Metode penelitian sampel adalah sampel jenuh dimana semua populasi dijadikan sampel, metode analisis dalam pengolahan data penelitian ini menggunakan metode analisis deskriptif, uji korelasi product moment pearson, koefisien determinasi dan uji hipotesis (test).

Hasil. Hasil penelitian ini menunjukkan bahwa terdapat pengaruh yang signifikan antara Kompetensi terhadap Kinerja Karyawan dengan nilai regresi $Y=17,85+0,685 \mathrm{X}$ yang artinya apabila setiap penambahan 1 (satu) poin variabel kompetensi maka akan meningkatkan kinerja sebesar 0,607 kali dengan kecepatan konstan. sebesar 17,85. Nilai koefisien korelasi sebesar 0,7402 artinya variabel kompetensi mempunyai tingkat hubungan yang kuat dengan variabel kinerja. Dari perhitungan Koefisien Determinasi (KD) diperoleh sebesar 0,5479, dapat disimpulkan bahwa kompetensi memberikan kontribusi terhadap kinerja pegawai sebesar
\end{abstract}


$54,79 \%$ sedangkan sisanya sebesar $45,21 \%$ dipengaruhi oleh faktor lain yang tidak diteliti. Pengujian hipotesis dengan menggunakan uji statistik $t_{\text {hitung }}$ diperoleh $t_{\text {hitung }}>t_{\text {tabel }}$ atau 7,461> 2,013 yang artinya Ha diterima dan Ho ditolak, artinya terdapat hubungan yang signifikan antara kompetensi dengan kinerja pegawai pada Biro Pengembangan Operasi Mabes Polri Jakarta.

Implikasi. Biro Operasional Mabes Polri harus rutin melakukan pelatihan kepada seluruh pegawai sesuai dengan standar manajemen agar pegawai dapat menyelesaikan tugas dengan cepat dan tepat, serta selalu konsisten dalam memberikan waktu kepada pegawai untuk menyelesaikan tugas guna mencapai target hasil kerja yang telah ditetapkan. efektif dan efisien.

Kata Kunci: Kompetensi dan Kinerja

\section{Pendahuluan}

Biro Pembinaan Operasi adalah sebuah Sub Satuan Kerja yang berada dibawah Satuan Kerja Staf Operasi Kapolri yang berada ditingkat Markas Besar Kepolisian Negara Republik Indonesia (Mabes Polri) dan memiliki fungsi kerja sebagai perencana, pelatihan, pemenuhan dukungan personil dan materiil serta evaluasi seluruh Operasi Kepolisian yang ada di Indonesia. Biro Pembinaan Operasi memiliki 48 pegawai. Sesuai dengan Peraturan Menteri Pendayagunaan Aparatur Negara dan Reformasi Birokrasi Republik Indonesia Nomor 38 Tahun 2017 bahwa pengertian dari Pegawai Negeri Sipil adalah Warga Negara Indonesia yang memenuhi syarat tertentu, diangkat sebagai pegawai ASN secara tetap oleh Pejabat Pembina Kepegawaian untuk menduduki jabatan Pemerintah. dapat disimpulkan 6 pegawai memiliki 2 kompetensi, 2 pegawai memiliki 3 kompetensi, dan 2 pegawai memiliki 1 kompetensi. Untuk kompetensi yang paling banyak di miliki adalah Memiliki kemampuan menguasai emosi dengan baik dalam menjalankan tugas dan mampu menyelesaikan tugas dengan cepat, tepat dan benar. Hal ini menunjukkan bahwa masih sedikitnya pegawai yang memiliki kompetensi yang baik.

Dapat dilihat bahwa personel yang memiliki pangkat dan jabatan sama namun memiliki kompetensi yang berbeda dapat mengakibatkan penilaian pencapaian kinerja yang berbeda pula. NIlai pencapaian Kinerja diperoleh berdasarkan sasaran pegawai selama 1 tahun dikali $60 \%$ ditambah jumlah nilai perilaku kerja yang meliputi orientasi pelayanan, integritas, komitmen, disiplin, kerjasama, kepemimpinan dan akan di ambil nilai rata-rata dikalikan $40 \%$. Apabila nilai sasaran kerja pegawai dijumlahkan dengan nilai perilaku kerja dengan hasil dibawah 50 dikategorikan "buruk", dibawah 60 dikategorikan "sedang", dibawah 75 dikategorikan "cukup", dibawah 90,99 dikategorikan "baik" dan diatas 91 dikategorikan "sangat baik".

Tabel 1. Standar kompetensi pegawai

\begin{tabular}{|c|l|c|c|c|c|c|c|c|c|c|c|}
\hline \multirow{2}{*}{ No } & \multicolumn{1}{|c|}{$\begin{array}{c}\text { Kompetensi Yang } \\
\text { Dimiliki }\end{array}$} & \multicolumn{7}{|c|}{ Personel Biro Pembinaan Operasi } \\
\cline { 2 - 11 } & Wati & Toni & Sigit & Ani & Rian & Devi & Ardi & Susi & Ineu & Siti \\
\hline $\begin{array}{l}\text { Memiliki kemampuan } \\
\text { menguasai emosi dengan } \\
\text { baik dalam menjalankan } \\
\text { tugas }\end{array}$ & $\mathrm{X}$ & & & & & & & & & \\
\hline 2 & $\begin{array}{l}\text { Mampu menyelesaikan } \\
\text { tugas dengan cepat, tepat } \\
\text { dan benar }\end{array}$ & & $\mathrm{X}$ & & $\mathrm{X}$ & $\mathrm{X}$ & & & & $\mathrm{X}$ & $\mathrm{X}$ \\
\hline 3 & $\begin{array}{l}\text { Memiliki pengetahuan } \\
\text { yang luas }\end{array}$ & & $\mathrm{X}$ & $\mathrm{X}$ & & & & & $\mathrm{X}$ & $\mathrm{X}$ \\
\hline 4 & $\begin{array}{l}\text { Mampu menyusun } \\
\text { laporan dengan akurat } \\
\text { dan sistematis }\end{array}$ & $\mathrm{X}$ & & $\mathrm{X}$ & & $\mathrm{X}$ & & $\mathrm{X}$ & & & \\
\hline 5 & $\begin{array}{l}\text { Mampu menjalankan } \\
\text { tugas sesuai dengan } \\
\text { standar pekerjaan }\end{array}$ & & $\mathrm{X}$ & & & $\mathrm{X}$ & & & & $\mathrm{X}$ & \\
\hline
\end{tabular}


Dari hasil survey di atas, dapat disimpulkan 6 pegawai memiliki 2 kompetensi, 2 pegawai memiliki 3 kompetensi, dan 2 pegawai memiliki 1 kompetensi. Untuk kompetensi yang paling banyak di miliki adalah Memiliki kemampuan menguasai emosi dengan baik dalam menjalankan tugas dan mampu menyelesaikan tugas dengan cepat, tepat dan benar. Hal ini menunjukkan bahwa masih sedikitnya pegawai yang memiliki kompetensi yang baik. Penilaian kinerja pada Biro Pembinaan operasi menggunakan formulir penilaian prestasi kerja bagi pegawai setiap 1 tahun dengan penilaian sesuai dengan tugas pokok jabatan. Namun dikarenakan kompetensi personil yang kurang dan jabatan yang dimiliki tidak sesuai dengan tugas yang dilaksanakan sehari-hari sehingga mengakibatkan penilaian kinerja pegawai kurang efektif. Berikut adalah tabel Penilaian Kinerja Pegawai pada Biro Pembinaan Operasi Mabes Polri selama 1 tahun periode tahun 2018:

Tabel 2. Hasil Kinerja Pegawai pada Tahun 2018

\begin{tabular}{|c|c|c|c|c|c|}
\hline NO & NAMA & PANGKAT & JABATAN & $\begin{array}{c}\text { NILAI } \\
\text { PENCAPAIAN KINERJA }\end{array}$ & KATEGORI \\
\hline 1 & WATI & PENATA & PERWIRA ADMINISTRASI & 70,23 & CUKUP \\
\hline 2 & TONI & PENATA & PERWIRA ADMINISTRASI & 74.88 & CUKUP \\
\hline 3 & SIGIT & PENATA & PERWIRA ADMINISTRASI & 68.90 & CUKUP \\
\hline 4 & ANI & PENATA & PERWIRA ADMINISTRASI & 72.34 & CUKUP \\
\hline 5 & RIAN & PENATA & PERWIRA ADMINISTRASI & 87,02 & BAIK \\
\hline 6 & DEVI & PENATA & PERWIRA ADMINISTRASI & 58,70 & SEDANG \\
\hline 7 & ARDI & PENATA & PERWIRA ADMINISTRASI & 65,40 & CUKUP \\
\hline 8 & SUSI & PENATA & PERWIRA ADMINISTRASI & 55,35 & SEDANG \\
\hline 9 & INEU & PENATA & PERWIRA ADMINISTRASI & 85,86 & BAIK \\
\hline 10 & SITI & PENATA & PERWIRA ADMINISTRASI & 69,55 & CUKUP \\
\hline
\end{tabular}

Sumber : Biro Pengembangan Operasi Mabes Polri

Dari tabel diatas dapat dilihat bahwa personel yang memiliki pangkat dan jabatan sama namun memiliki kompetensi yang berbeda dapat mengakibatkan penilaian pencapaian kinerja yang berbeda pula. NIlai pencapaian Kinerja diperoleh berdasarkan sasaran pegawai selama 1 tahun dikali $60 \%$ ditambah jumlah nilai perilaku kerja yang meliputi orientasi pelayanan, integritas, komitmen, disiplin, kerjasama, kepemimpinan dan akan di ambil nilai rata-rata dikalikan 40\%. Apabila nilai sasaran kerja pegawai dijumlahkan dengan nilai perilaku kerja dengan hasil dibawah 50 dikategorikan "buruk", dibawah 60 dikategorikan "sedang", dibawah 75 dikategorikan "cukup", dibawah 90,99 dikategorikan "baik" dan diatas 91 dikategorikan "sangat baik".

Dari gambaran penilaian di atas, dapat dilihat bahwa kompetensi yang dimiliki seorang pegawai sangat berperan dalam pencapaian nilai kinerja karena di dalam formulir penilaian kinerja terdapat target yang harus dipenuhi oleh pegawai tersebut, bagaimana seorang pegawai dapat berhasil dengan baik dalam memenuhi target tugas pokoknya apabila tidak memiliki kompetensi yang dapat mendukung pencapaian target. Berdasarkan permasalahan diatas maka peneliti mengambil judul "Pengaruh Kompetensi Terhadap Kinerja Pegawai Pada Biro Pembinaan Operasi Mabes Polri Jakarta".

\section{Kajian Pustaka dan Hipotesis}

Kompetensi. Menurut Wibowo (2016:271) Kompetensi adalah suatu kemampuan untuk melaksanakan atau melakukan suatu pekerjaan atau tugas yang dilandasi atas keterampilan dan pengetahuan serta didukung oleh sikap kerja yang dituntut oleh pekerjaan tersebut. Dengan demikian, kompetensi menunjukkan keterampilan atau pengetahuan yang dicirikan oleh profesionalisme dalam suatu bidang tertentu sebagai sesuatu yang terpenting, sebagai unggulan bidang tersebut. Menurut Donni Juni Priansa (2017:87) kompetensi adalah peta kapasitas pegawai atas atribut pekerjaan yang diembannya, yang merupakan kumpulan 
kemampuan, keterampilan, kematangan, pengalaman, keefektifan, keefisienan dan kesuksesan dalam mengemban tanggung jawab pekerjaan.

Kinerja. Menurut A.A. Anwar Prabu Mangkunegara (2015:9) kinerja karyawan (prestasi kerja) adalah hasil kerja secara kualitas dan kuantitas yang dicapai oleh seseorang karyawan dalam melaksanakan tugasnya sesuai dengan tanggung jawab yang diberikan kepadanya. Selanjutnya menurut Veithzal Rivai (2018:15) kinerja adalah kesediaan seseorang atau sekelompok orang untuk melakukan sesuatu kegiatan dan menyempurnakan sesuai dengan tanggung jawabnya dengan hasil seperti yang diharapkan. Menurut Kasmir (2018:182) kinerja adalah hasil kerja dan perilaku kerja yang telah dicapai dalam menyelesaikan tugas-tugas dan tanggung jawab yang diberikan dalam suatu periode tertentu. Menurut Donni Juni Priansa (2017:48) kinerja merupakan perwujudan dari kemampuan dalam bentuk karya nyata atau merupakan hasil kerja yang dicapai pegawai dalam mengemban tugas dan pekerjaan yang berasal dari perusahaan.

Sedangkan Wirawan berpendapat kinerja adalah keluaran yang dihasilkan oleh fungsifungsi atau indikator-indikator suatu pekerjaan atau suatu profesi dalam waktu tertentu yang diukur melalui hasil kerja, perilaku kerja, dan sifat pribadi yang berhubungan dengan pekerjaan (2012:166).Jadi, kinerja adalah prestasi kerja atau hasil kerja (output) baik kualitas maupun kuantitas yang dicapai SDM persatuan periode waktu dalam melaksakan tugas kerjanya sesuai dengan tanggung jawab yang diberikan oleh seseorang atau sekelompok.

Hipotesis. Menurut Sugiyono (2014:94) berpendapat "Hipotesis adalah suatu dugaan atau jawaban yang bersifat sementara dimana kebenaranya masih diragukan, sebab itu harus diuji secara empiris". Berdasarkan perumusan masalah yang ditetapkan maka rumusan hipotesis yang dibuat adalah sebagai berikut:

Ho: Tidak terdapat pengaruh yang signifikan antara kompetensi terhadap kinerja pegawai pada Biro Pembinaan Operasi Mabes Polri.

Ha: Terdapat pengaruh yang signifikan antara kompetensi terhadap kinerja pegawai pada Biro Pembinaan Operasi Mabes Polri.

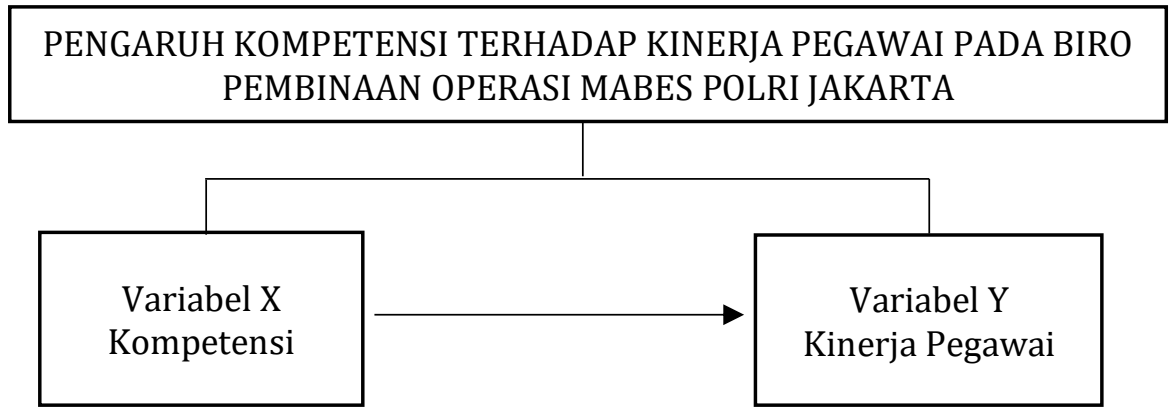

Gambar 1. Model Penelitian

\section{Metode Penelitian}

Sifat penelitian ini bersifat deskriptif dengan pendekatan kuantitatif berdasarkan hasil kuesioner. Metode deskriptif dengan pendekatan kuantitatif menurut Sugiyono (2015:10) "metode kuantitatif dapat diartikan sebagai metode penelitian yang berlandaskan pada filsafat postivisme, digunakan untuk meneliti pada populasi dan sampel tertentu, pengumpulan data menggunakan instrumen penelitian, analisis data bersifat kuantitatif/statistik, dengan tujuan untuk menguji hipotesis yang telah ditetapkan". Populasi dalam penelitian ini yaitu pegawai pada Biro Pembinaan Operasi Mabes Polri Jakarta dan sampel yang digunakan yaitu seluruh pegawai pada Biro Pembinaan Operasi Mabes Polri Jakarta yang berjumlah 48 personil.

\section{Teknik Pengumpulan Data}

Dalam penelitian ini teknik pengumpulan data (data primer dan data sekunder) yang digunakan yaitu dengan cara melakukan observasi (pengamatan), kuesioner (angket), dan melakukan studi kepustakaan untuk mencari landasan teoritis yang berhubungan dengan judul penelitian di atas. 


\section{Teknik Analisis Data}

Dalam penelitian analisis data sangat penting, dimana data tersebut dikelompokkan berdasarkan variabel dan jenisnya, lalu data ditabulasi dan disajikan berdasarkan variabel yang diteliti, dilakukan perhitungan data untuk menjawab rumusan masalah dan sebagai pembuktian dari hipotesis yang telah diajukan. Adapun teknik analisis data yang digunakan dalam melakukan penelitian ini adalah: uji validitas, uji reliabilitas, uji koefisien korelasi, uji koefisien determinasi, uji analisis regresi linier sederhana dan uji hipotesis.

\section{Hasil Penelitian dan Pembahasan}

\section{Gambaran Umum Biro Pembinaan Operasi Mabes Polri Jakarta}

Sesuai dengan Peraturan Kepala Kepolisian Negara Republik Indonesia Nomor 6 Tahun 2017 tentang susunan organisasi dan tata kerja satuan Organisasi pada tingkat Markas Besar Kepolisian Negara Republik Indonesia bahwa Staf Operasi Polri yang selanjutnya disebut Sops Polri adalah unsur pengawas dan pembantu pimpinan dalam bidang menajemen operasi kepolisian, kegiatan operasional terpadu dan kerja sama Kementeria/Lembaga pada tingkat Mabes Polri yang berada di bawah Kapolri. Staf Operasi Polri meliputi Bagian Perencanaan dan administrasi, urusan keuangan, Biro pengkajian dan strategi, Biro pembinaan operasi, Biro Kerjsama Kementerian Lembaga dan Biro pengendalian operasi. Biro Pembinaan Operasi berada di bawah struktur organisasi Staf Operasi Mabes Polri dengan dipimpin oleh Kepala Biro pembinaan operasi bertugas menyusun rencana dan pengendalian, dukungan administrasi, pelatihan pra operasi, melaksanakan analisis dan evaluasi atas penyelenggaran operasi kepolisian, termasuk pengawasan dan pembinaan atas pelaksanaan operasi kepolisian tingkat kewilayahan.

\section{Deskriptif Data Responden}

Adapun responden dalam penelitian ini adalah personil/pegawai yang bekerja pada Biro Pembinaan Operasi Mabes Polri Jakarta yang berjumlah 48 responden. Teknik ini digunakan untuk mengungkap gambaran mengenai data responden secara deskriptif dengan cara mengintreprestasikan hasil pengolahan melalui tabulasi frekuensi guna menyikapi kecenderung data mengenai jenis kelamin, umur, pendidikan dalan lama bekerja. Berikut ini deskripsi mengenai identitas responden yaitu sebagai berikut:

Tabel 3. Karakteristik Responden

\begin{tabular}{|c|c|c|}
\hline Keterangan & Jumlah & Persentase (\%) \\
\hline \multicolumn{3}{|l|}{ Jenis Kelamin } \\
\hline Laki-Laki & 35 & $73 \%$ \\
\hline Perempuan & 13 & $27 \%$ \\
\hline TOTAL & 48 & $100 \%$ \\
\hline \multicolumn{3}{|l|}{ Umur } \\
\hline 20-30 Tahun & 3 & $6 \%$ \\
\hline 31-40 Tahun & 11 & $23 \%$ \\
\hline 41-50 Tahun & 11 & $23 \%$ \\
\hline$\geq 50$ Tahun & 23 & $48 \%$ \\
\hline TOTAL & 48 & $100 \%$ \\
\hline \multicolumn{3}{|l|}{ Pendidikan } \\
\hline SMA/Sederajat & 17 & $35 \%$ \\
\hline Diploma (D3) & 0 & $0 \%$ \\
\hline Sarjana (S1) & 20 & $42 \%$ \\
\hline Magister (S2) & 11 & $23 \%$ \\
\hline TOTAL & 48 & $100 \%$ \\
\hline
\end{tabular}

Sumber: Data primer yang telah diolah 


\section{Distribusi Jawaban Kuesioner}

Tabel 4. Distribusi Jawaban Responden Variabel X (Kompetensi)

\begin{tabular}{|c|c|c|c|c|c|c|c|c|c|}
\hline \multirow{2}{*}{ No } & \multirow{2}{*}{ PERNYATAAN } & \multicolumn{5}{|c|}{ JAWABAN } & \multirow{2}{*}{ Sampel } & \multirow{2}{*}{ Total } & \multirow{2}{*}{ Rata-rata } \\
\hline & & SS & $\mathbf{S}$ & $\mathbf{R}$ & TS & STS & & & \\
\hline \multicolumn{10}{|c|}{ Pengetahuan } \\
\hline 1 & $\begin{array}{l}\text { seorang } \\
\text { betapa penawi harus }\end{array}$ & 20 & 23 & 3 & 1 & 1 & 48 & 204 & 4,25 \\
\hline 2 & $\begin{array}{lcc}\begin{array}{l}\text { Seorang pegawai } \\
\text { pengetahuan }\end{array} & \text { mempunyai } \\
\text { jabatan saya } & \text { sesuai } & \text { kompetensi } \\
\end{array}$ & 25 & 17 & 3 & 1 & 2 & 48 & 206 & 4,29 \\
\hline \multicolumn{10}{|c|}{ Pemahaman } \\
\hline 3 & $\begin{array}{l}\text { Seorang pegawai harus bisa } \\
\text { menyelesaikan suatu masalah dalam } \\
\text { tugasnya }\end{array}$ & 16 & 18 & 8 & 3 & 3 & 48 & 185 & 3,85 \\
\hline 4 & $\begin{array}{l}\text { Seorang pegawai menyelesaikan tugas } \\
\text { dengan cepat dan tepat }\end{array}$ & 31 & 8 & 0 & 4 & 5 & 48 & 200 & 4,17 \\
\hline \multicolumn{10}{|c|}{ Kemampuan/keterampilan } \\
\hline 5 & $\begin{array}{l}\text { Ketelitian dalam melaksanakan } \\
\text { pekerjaan adalah salah satu upaya } \\
\text { saya dalam menyelesaikan tugas }\end{array}$ & 19 & 18 & 5 & 6 & 0 & 48 & 194 & 4,04 \\
\hline 6 & $\begin{array}{l}\text { Pegawai mampu mengaplikasikan } \\
\text { pengetahuan kerja ke dalam bidang } \\
\text { pekerjaan }\end{array}$ & 17 & 15 & 10 & 5 & 1 & 48 & 186 & 3,88 \\
\hline \multicolumn{10}{|c|}{ Nilai } \\
\hline 7 & $\begin{array}{l}\text { Setiap pegawai wajib menjadi contoh } \\
\text { pribadi yang baik dilingkungan kerja } \\
\text { dan masyarakat }\end{array}$ & 16 & 10 & 12 & 6 & 4 & 48 & 172 & 3,58 \\
\hline 8 & $\begin{array}{l}\text { Segala sikap dan performa yang } \\
\text { dimiliki pegawai merupakan } \\
\text { cerminan dari pribadi pegawai }\end{array}$ & 24 & 12 & 7 & 5 & 0 & 48 & 199 & 4,15 \\
\hline \multicolumn{10}{|c|}{ Sikap } \\
\hline 9 & $\begin{array}{l}\text { Pegawai selalu patuh kepada } \\
\text { Kebijakan yang dibuat oleh Pimpinan }\end{array}$ & 19 & 18 & 6 & 5 & 0 & 48 & 195 & 4,05 \\
\hline 10 & $\begin{array}{l}\text { Mendapatkan teguran karena } \\
\text { melanggar aturan adalah hal wajar } \\
\text { yang harus diterima }\end{array}$ & 16 & 17 & 11 & 3 & 1 & 48 & 188 & 3,92 \\
\hline \multicolumn{10}{|c|}{ Minat } \\
\hline 11 & $\begin{array}{l}\text { Pegawai harus } \quad \text { selalu } \\
\text { melaksanakan } \\
\begin{array}{l}\text { manapun } \\
\text { tugas }\end{array}\end{array}$ & 21 & 16 & 7 & 1 & 3 & 48 & 195 & 4,06 \\
\hline 12 & $\begin{array}{l}\text { Seorang pegawai harus secara } \\
\text { sukarela dalam melaksanakan tugas } \\
\text { yang diberikan pimpinan }\end{array}$ & 19 & 16 & 5 & 4 & 4 & 48 & 186 & 3,88 \\
\hline \multicolumn{8}{|c|}{ Total Rata-rata Indikator } & 2310 & 4,01 \\
\hline & Rata-rata Pa & da Ind & rator & & & & & $\begin{array}{l}401,04 \\
2\end{array}$ & 4,01 \\
\hline
\end{tabular}

Sumber: Data primer yang telah diolah

Dari tabel di atas hasil jawaban responden variabel kompetensi (X) sebesar 4,01 yang terdapat pada rentang skala antara 3,40-4,19 dengan kriteria "Baik". Dibawah ini merupakan rentang skala yang digunakan oleh peneliti sebagai dasar pengambilan keputusan. 
Tabel 5. Rentang Skala

\begin{tabular}{|c|l|}
\hline Rentang Skala & \multicolumn{1}{|c|}{ Keterangan } \\
\hline $4,20-5,00$ & Sangat Baik \\
\hline $\mathbf{3 , 4 0}-\mathbf{4 , 1 9}$ & Baik \\
\hline $2,60-3,39$ & Cukup Baik \\
\hline $1,00-1,79$ & Sangat Tidak Baik \\
\hline
\end{tabular}

Sumber Sugiyono (2016:93)

Tabel 6. Jawaban Responden Indikator Variabel Kinerja Pegawai (Y)

\begin{tabular}{|c|c|c|c|c|c|c|c|c|c|}
\hline \multirow{2}{*}{ No } & \multirow{2}{*}{ PERNYATAAN } & \multicolumn{5}{|c|}{ JAWABAN } & \multirow{2}{*}{ Sampel } & \multirow{2}{*}{ Total } & \multirow{2}{*}{$\begin{array}{l}\text { Rata- } \\
\text { rata }\end{array}$} \\
\hline & & SS & $\mathbf{S}$ & $\mathbf{R}$ & ST & SS & & & \\
\hline \multicolumn{10}{|c|}{ Kualitas kerja } \\
\hline 1 & $\begin{array}{l}\text { Prestasi kerja yang baik merupakan } \\
\text { indikasi kesuksesan pengelolaan sumber } \\
\text { daya manusia dalam perusahaan }\end{array}$ & 21 & 19 & 1 & 5 & 2 & 48 & 196 & 4,08 \\
\hline 2 & $\begin{array}{l}\text { Loyalitas sangat diperlukan oleh setiap } \\
\text { pegawai }\end{array}$ & 18 & 22 & 7 & 0 & 1 & 48 & 200 & 4,17 \\
\hline \multicolumn{10}{|c|}{ Kuantitas kerja } \\
\hline 3 & $\begin{array}{l}\text { Pegawai selalu menyelesaikan pekerjaan } \\
\text { dengan standar yang telah ditentukan }\end{array}$ & 20 & 22 & 4 & 1 & 1 & 48 & 203 & 4,22 \\
\hline 4 & $\begin{array}{l}\text { Pegawai melakukan lembur kerja untuk } \\
\text { menyelesaikan tugas }\end{array}$ & 16 & 23 & 6 & 2 & 1 & 48 & 195 & 4,06 \\
\hline \multicolumn{10}{|c|}{ Waktu } \\
\hline 5 & $\begin{array}{l}\text { Pegawai selalu menyelesaikan tugas yang } \\
\text { diberikan dengan tepat waktu }\end{array}$ & 16 & 18 & 11 & 3 & 0 & 48 & 191 & 3,98 \\
\hline 6 & $\begin{array}{l}\text { Tenggang waktu yang diberikan pimpinan } \\
\text { untuk menyelesaikan tugas sudah disesuai } \\
\text { dengan timeline }\end{array}$ & 2 & 13 & 17 & 8 & 8 & 48 & 137 & 2,85 \\
\hline \multicolumn{10}{|c|}{ Penekanan biaya } \\
\hline 7 & $\begin{array}{l}\text { Biaya yang dikeluarkan dalam setiap } \\
\text { kegiatan sudah disesuaikan dengan indeks }\end{array}$ & 20 & 21 & 1 & 6 & 0 & 48 & 199 & 4,14 \\
\hline 8 & $\begin{array}{l}\text { Sebelum melaksanakan kegiatan terlebih } \\
\text { dahulu merencanakan anggaran }\end{array}$ & 11 & 15 & 12 & 6 & 4 & 48 & 167 & 3,48 \\
\hline \multicolumn{10}{|c|}{ Pengawasan } \\
\hline 9 & $\begin{array}{l}\text { Pimpinan berperan aktif dalam setiap } \\
\text { tugas yang dilakukan oleh pegawai }\end{array}$ & 13 & 18 & 8 & 6 & 3 & 48 & 176 & 3,67 \\
\hline 10 & $\begin{array}{l}\text { Pegawai selalu melaporkan hasil dari } \\
\text { pelaksanaan tugas kepada pimpinan }\end{array}$ & 25 & 16 & 2 & 3 & 2 & 48 & 203 & 4,23 \\
\hline \multicolumn{10}{|c|}{ Hubungan antar karyawan } \\
\hline 11 & $\begin{array}{l}\text { Pegawai mampu berkoor4,02dinasi } \\
\text { dengan unit lain dalam menjalankan } \\
\text { tugasnya }\end{array}$ & 18 & 21 & 5 & 3 & 1 & 48 & 196 & 4,08 \\
\hline 12 & $\begin{array}{l}\text { pegawai mampu menyelesaikan tugas } \\
\text { dalam bentuk tim kerja }\end{array}$ & 16 & 24 & 3 & 3 & 2 & 48 & 193 & 4,04 \\
\hline \multicolumn{8}{|c|}{ Total Rata-rata Indikator } & 2256 & 3,91 \\
\hline \multicolumn{8}{|c|}{ Rata-rata Pada Indikator } & 391,67 & 3,91 \\
\hline
\end{tabular}

Sumber: Data primer yang telah diolah

Dari tabel di atas hasil jawaban responden variabel kinerja pegawai $(\mathrm{Y})$ sebesar 3,91 yang terdapat pada rentang skala antara 3,40-4,19 dengan kriteria "Baik". Dibawah ini merupakan rentang skala yang digunakan oleh peneliti sebagai dasar pengambilan keputusan.

Tabel 7. Rentang Skala

\begin{tabular}{|c|l|}
\hline Rentang Skala & \multicolumn{1}{|c|}{ Keterangan } \\
\hline $4,20-5,00$ & Sangat Baik \\
\hline $\mathbf{3 , 4 0}-\mathbf{4 , 1 9}$ & Baik \\
\hline $2,60-3,39$ & Cukup Baik \\
\hline $1,00-1,79$ & Sangat Tidak Baik \\
\hline
\end{tabular}

Sumber Sugiyono (2016:93) 


\section{Uji Validitas Instrumen}

Uji validitas berguna untuk mengetahui apakah ada pernyataan pada kuesioner yang harus diganti karena dianggap tidak relevan. Untuk menguji validitas setiap instrument, rumus yang digunakan adalah koefisien korelasi product moment sebagai berikut:

$$
r x y=\frac{\mathrm{n}\left(\sum \mathrm{xy}\right)-\left(\sum \mathrm{x}\right)\left(\sum y\right)}{\sqrt{\left\{n \cdot \sum x^{2}-\left(\sum x\right)^{2}\right\}\left\{n \cdot \sum y^{2}-\left(\sum y\right)^{2}\right\}}}
$$

Sumber: Sugiyono (2016: 361)

Keterangan:

$$
\begin{array}{ll}
\text { rxy } & =\text { koefisien korelasi antar } \mathrm{X} \text { dan } \mathrm{Y} \\
\mathrm{n} & =\text { jumlah responden } \\
\mathrm{x} & =\text { skor item kuesioner } \\
\mathrm{y} & =\text { total skor item kuesioner } \\
\sum \mathrm{x}^{2} & =\text { jumlah kuadrat seluruh skor } \mathrm{X} \\
\sum \mathrm{y}^{2} & =\text { jumlah kuadrat seluruh skor } \mathrm{Y}
\end{array}
$$

Kriteria uji validitas:

Jika $r_{\text {hitung }}>r_{\text {tabel }}$ maka valid dan Jika $r_{\text {hitung }}<r_{\text {tabel }}$ maka tidak valid

Tabel 8. uji validitas Kompetensi variabel $(\mathrm{X})$

\begin{tabular}{|c|c|c|c|}
\hline Pernyataan & $\mathrm{r}_{\text {hitung }}$ & $\mathrm{r}_{\text {tabel }}$ & Keterangan \\
\hline 1 & 0,3797 & 0,2845 & Valid \\
\hline 2 & 0,4638 & 0,2845 & Valid \\
\hline 3 & 0,4736 & 0,2845 & Valid \\
\hline 4 & 0,3617 & 0,2845 & Valid \\
\hline 5 & 0,4521 & 0,2845 & Valid \\
\hline 6 & 0,3466 & 0,2845 & Valid \\
\hline 7 & 0,3953 & 0,2845 & Valid \\
\hline 8 & 0,4287 & 0,2845 & Valid \\
\hline 9 & 0,3873 & 0,2845 & Valid \\
\hline 10 & 0,4387 & 0,2845 & Valid \\
\hline 11 & 0,3905 & 0,2845 & Valid \\
\hline 12 & 0,3988 & 0,2845 & Valid \\
\hline
\end{tabular}

Sumber: Data primer yang telah diolah

Berdasarkan tabel diatas dapat kita ketahui bahwa semua butir pernyataan pada variabel stress kerja $(X)$ adalah valid, karena nilai $\mathbf{r}$ hitung $>$ dari nilai $r_{\text {tabel }}(0,2845)$. Dengan tingkat validitas paling tinggi adalah butir ke 3 dengan $r_{\text {hitung }} 0,4736$ dan tingkat validitas paling rendah pada butir ke 6 dengan $r_{\text {hitung }} 0,3466$.

Tabel 9. uji validitas Kinerja Pegawai (Y)

\begin{tabular}{|c|c|c|c|}
\hline Pernyataan & $\mathrm{r}_{\text {hitung }}$ & $\mathrm{r}_{\text {tabel }}$ & Keterangan \\
\hline 1 & 0,4016 & 0,2845 & Valid \\
\hline 2 & 0,3656 & 0,2845 & Valid \\
\hline 3 & 0,4170 & 0,2845 & Valid \\
\hline 4 & 0,3564 & 0,2845 & Valid \\
\hline 5 & 0,2854 & 0,2845 & Valid \\
\hline 6 & 0,2909 & 0,2845 & Valid \\
\hline 7 & 0,3446 & 0,2845 & Valid \\
\hline 8 & 0,4020 & 0,2845 & Valid \\
\hline 9 & 0,3519 & 0,2845 & Valid \\
\hline 10 & 0,3583 & 0,2845 & Valid \\
\hline 11 & 0,3360 & 0,2845 & Valid \\
\hline 12 & 0,4805 & 0,2845 & Valid \\
\hline
\end{tabular}

Sumber: Data primer yang telah diolah 
Berdasarkan tabel diatas dapat kita ketahui bahwa semua butir pernyataan pada variabel Kinerja $(\mathrm{Y})$ adalah valid, karena nilai $\mathrm{r}_{\text {hitung }}$ dari keseluruhan pernyataan yang ada menunjukan angka $>$ dari nilai $r_{\text {tabel }}(0,2845)$. Dengan tingkat validitas paling tinggi adalah butir ke 12 dengan $r_{\text {hitung }} 0,4805$ dan tingkat validitas paling rendah pada butir ke 5 dengan $r_{\text {hitung }}$ 0,2854 .

\section{Uji Reliabilitas Instrumen}

Menurut Suharsimi Arikunto (2013:221) menyatakan bahwa "Reliabilitas menunjukkan pada suatu pengertian bahwa suatu instrumen dapat dipercaya untuk digunakan sebagai alat pengumpulan data karena instrumen tersebut sudah baik". Cara menghitung tingkat reliabilitas suatu data yaitu dengan menggunakan rumus Alpha Cronbach berikut:

$$
r_{11}=\left[\frac{k}{k-1}\right]\left[1-\frac{\sum \sigma_{b}^{2}}{\sigma_{1}^{2}}\right]
$$

Sumber: Suharsimi Arikunto (2013:223)

Keterangan:

$\mathrm{r}_{11} \quad=$ Koefisien reliabilitas

$\mathrm{k} \quad=$ Jumlah butir pertanyaan

$\sum \sigma_{b}{ }^{2}=$ Jumlah variansi butir pertanyaan

$\sigma_{1}^{2} \quad=$ variansi total

Jumlah varians skor setiap item dan varians total, dapat dihitung dengan menggunakan rumus sebagai berikut:

$$
\sigma_{i}^{2}=\frac{\sum X_{1}^{2}-\frac{\left(\sum X_{i}\right)^{2}}{n}}{n}
$$

Sumber: Suharsimi Arikunto (2013:227)

Sedangkan untuk menghitung vartians total, digunakan rumus:

$$
\sigma_{t}^{2}=\frac{\sum Y_{t}^{2}-\frac{\left(\sum Y_{t}\right)^{2}}{n}}{n}
$$

Sumber: Suharsimi Arikunto (2013:227)

Keterangan:

$\sigma_{i}^{2}=$ variansi tiap item

$\sigma_{t}^{2} \quad=$ variansi tiap item

$X_{11} \quad=$ Jawaban responden untuk setiap butir soal

$\sum \mathrm{Y}_{\mathrm{t}} \quad=$ Total jawaban responden untuk setiap butir pertanyaan

$n \quad=$ Jumlah responden

Untuk memberi interpretasi pengujian reliabilitas instrumen, maka dapat dilihat pada tabel di bawah ini:

Tabel 10. Kriteria Pengujian Reliabilitas Instrumen

\begin{tabular}{|c|c|}
\hline Kriteria Reliabilitas & Keterangan \\
\hline $\mathrm{R} 11<0,20$ & Reliabilitas Sangat Rendah \\
\hline $0,20<\mathrm{r} 110,40$ & Reliabilitas Rendah \\
\hline $0,40<\mathrm{r} 110,70$ & Reliabilitas sedang \\
\hline $0,70<\mathrm{r} 110,90$ & Reliabilitas Tinggi \\
\hline $0,90<\mathrm{r} 111,00$ & Reliabilitas Sangat Tinggi \\
\hline
\end{tabular}

Sumber: Suharsimi Arikunto (2010:93) 
Tabel 11. Hasil Uji Reabilitas Variabel Kompetensi (X)

\begin{tabular}{|c|c|c|c|}
\hline Item Pernyataan & $\mathbf{R}_{\text {hitung }}$ & $\mathbf{R}_{\text {tabel }}$ & Keterangan \\
\hline 1 & 0,6875 & 0,2845 & RELIABEL \\
\hline 2 & 0,9566 & 0,2845 & RELIABEL \\
\hline 3 & 1,2912 & 0,2845 & RELIABEL \\
\hline 4 & 1,8889 & 0,2845 & RELIABEL \\
\hline 5 & 0,9983 & 0,2845 & RELIABEL \\
\hline 6 & 1,1510 & 0,2845 & RELIABEL \\
\hline 7 & 1,6597 & 0,2845 & RELIABEL \\
\hline 8 & 1,4336 & 0,2845 & RELIABEL \\
\hline 9 & 0,9336 & 0,2845 & RELIABEL \\
\hline 10 & 0,9931 & 0,2845 & RELIABEL \\
\hline 11 & 1,2253 & 0,2845 & RELIABEL \\
\hline 12 & 1,5677 & 0,2845 & RELIABEL \\
\hline \multicolumn{3}{|c|}{$\sum \sigma_{b}^{2}$} & 14,7865 \\
\hline \multicolumn{3}{|c|}{$\sigma_{1}^{2}$} & 29,0816 \\
\hline \multicolumn{3}{|c|}{$r_{11}$} & 0,5363 \\
\hline
\end{tabular}

Sumber: Data primer yang telah diolah

Berdasarkan tabel diatas dapat kita ketahui bahwa semua butir pernyataan pada variabel Kompetensi $(\mathrm{X})$ adalah reliabel, karena nilai $\mathrm{r}_{\text {hitung }}$ dari keseluruhan pernyataan yang ada menunjukan angka $>$ dari nilai $r_{\text {tabel }}(0,2845)$. Dan hasil uji reliabilitas di atas $r_{11} 0,5363$ menunjukkan tingkat reliabilitas sedang karena termasuk kedalam kriteria reliabilitas $0,40<$ r11 0,70 "Reliabilitas Sedang".

Tabel 12. Hasil Uji Reabilitas Variabel Kinerja (Y)

\begin{tabular}{|c|c|c|c|}
\hline Item Pernyataan & $\mathbf{R}_{\text {hitung }}$ & $\mathbf{R}_{\text {tabel }}$ & Keterangan \\
\hline 1 & 1,3681 & 0,2845 & RELIABEL \\
\hline 2 & 0,8086 & 0,2845 & RELIABEL \\
\hline 3 & 0,7183 & 0,2845 & RELIABEL \\
\hline 4 & 0,8086 & 0,2845 & RELIABEL \\
\hline 5 & 1,0139 & 0,2845 & RELIABEL \\
\hline 6 & 1,2483 & 0,2845 & RELIABEL \\
\hline 7 & 0,9306 & 0,2845 & RELIABEL \\
\hline 8 & 1,7483 & 0,2845 & RELIABEL \\
\hline 9 & 1,7500 & 0,2845 & RELIABEL \\
\hline 10 & 1,4440 & 0,2845 & RELIABEL \\
\hline 11 & 1,3086 & 0,2845 & RELIABEL \\
\hline 12 & 1,0169 & 0,2845 & RELIABEL \\
\hline \multicolumn{3}{|c|}{$\sigma_{1}^{2}$} & 14,1642 \\
\hline$\sigma_{11}^{2}$ & 19,5416 \\
\hline
\end{tabular}

Sumber: Data primer yang telah diolah

Berdasarkan tabel diatas dapat kita ketahui bahwa semua butir pernyataan pada variabel Kinerja (Y) adalah reliabel, karena nilai $r_{\text {hitung }}$ dari keseluruhan pernyataan yang ada menunjukan angka $>$ dari nilai $r_{\text {tabel }}(0,2845)$. Dan hasil uji reliabilitas di atas $r_{11} 0,3002$ menunjukkan tingkat reliabilitas sedang karena termasuk kedalam kriteria reliabilitas $0,20<$ r11 0,40 "Reliabilitas Rendah". 


\section{Analisis Regresi Linier Sederhana}

Analisis koefisien korelasi dimaksudkan untuk mengetahui tingkat hubungan antara variabel independen dengan variabel dependen. Dalam menganalisa hubungan variabel $x$ terhadap variabel $y$ pada Biro Pembinaan Operasi Mabes Polri, peneliti menggunakan metode koefisien korelasi. Rumus yang digunakan untuk menghitung hubungan antara variabel $x$ dan variabel $y$, adalah korelasi product moment.

$r_{x y}=\frac{n \cdot\left(\sum x y\right)-\left(\sum x\right)\left(\sum y\right)}{\sqrt{\left\{n \cdot \sum x^{2}-\left(\sum x\right)^{2}\right\}\left\{n \cdot \sum y^{2}-\left(\sum y\right)^{2}\right\}}}$

Keterangan:

$\mathrm{r}_{\mathrm{xy}} \quad=$ Koefisien korelasi variabel $x$ dan $y$

$\mathrm{n} \quad=$ Jumlah sampel

$\sum \mathrm{X} \quad=$ Jumlah skor total variabel $x$

$\sum \mathrm{Y}=$ Jumlah skor total variabel $y$

$\sum \mathrm{X}^{2} \quad$ = Jumlah kuadrat seluruh skor $x$

$\sum \mathrm{Y}^{2} \quad$ = Jumlah kuadrat seluruh skor $y$

$\sum \mathrm{XY}=$ Jumlah skor total variabel $\mathrm{x}$ dan $\mathrm{y}$

Diketahui :

$\begin{aligned} \mathrm{n} & =48 \\ \sum \mathrm{X} & =2306 \\ \sum \mathrm{Y} & =2256 \\ \sum \mathrm{X}^{2} & =112180 \\ \sum \mathrm{Y}^{2} & =106970 \\ \sum \mathrm{X} . \mathrm{Y} & =109229\end{aligned}$

Rumus :

$$
\begin{aligned}
r_{x y} & =\frac{n\left(\sum X Y\right)-\left(\sum X\right)\left(\sum Y\right)}{\sqrt{\left\{\left(n \sum X^{2}-\left(\sum X\right)^{2}\right)\left(n \sum Y^{2}-\left(\sum Y\right)^{2}\right)\right\}}} \\
& =\frac{48(109229)-(2306)(2256)}{\sqrt{\left(\left\{48.112180-(2306)^{2}\right)\left(48.106970-(2256)^{2}\right\}\right.}} \\
& =\frac{5242992-5202336}{\sqrt{\{(5384640-5317636)(5134560-5089536)\}}} \\
& =\frac{40656}{\sqrt{\{(67004)(45024)\}}} \\
& =\frac{40656}{\sqrt{3016788096}} \\
& =\frac{40656}{54925,2956}=0,7402
\end{aligned}
$$

Tabel 13. Pedoman Untuk Memberikan Interprestasi Koefisien Korelasi

\begin{tabular}{|c|c|}
\hline Interval Korelasi & Tingkat Hubungan \\
\hline $0,00-0,199$ & Sangat rendah \\
\hline $0,20-0,399$ & Rendah \\
\hline $0,40-0,599$ & Sedang \\
\hline $\mathbf{0 , 6 0}-\mathbf{0 , 7 9 9}$ & Kuat \\
\hline $0,80-1,000$ & Sangat kuat \\
\hline
\end{tabular}

Sumber: Sugiyono (2015:184)

Berdasarkan hasil analisa di atas dengan menggunakan korelasi product moment didapat nilai $r_{\mathrm{xy}}$ sebesar 0,7402 yang artinya terdapat hubungan positif yang kuat antara kompetensi terhadap kinerja pegawai di Biro Pembinaan Operasi Mabes Polri. 


\section{Koefisien Determinasi}

Untuk mengetahui besar persentase kontribusi antara Kompetensi terhadap kinerja pegawai pada Biro Pembinaan Operasi Mabes Polri, di ukur dengan koefisien determinasi rumus sebagai berikut :

$$
\begin{aligned}
\mathrm{KD} & =\mathrm{r}^{2} \times 100 \% \\
& =0,74022^{2} \times 100 \% \\
& =0,5479 \times 100 \% \\
\mathrm{KD} & =54,79 \%
\end{aligned}
$$

Nilai koefisien determinasi $\mathrm{r}=54,79 \%$ nilai ini menunjukkan bahwa kontribusi variabel $x$ (kompetensi) berhubungan dengan variabel $y$ (kinerja) sebesar 54,79\%, sedangkan selebihnya yaitu $(100 \%-54,79 \%)=45,21 \%$ dipengaruhi oleh faktor-faktor lain yang tidak diteliti.

\section{Analisis Uji Regresi Linier Sederhana}

Regresi Linier Sederhana digunakan untuk memprediksi besaran nilai variable terikat yang dipengaruhi oleh satu variabel bebas. Persamaan Regresi Linier Sederhana dinyatakan dengan rumus sebagai berikut:

$$
\mathrm{Y}=\mathrm{a}+\mathrm{bX}
$$

Untuk mengetahui nilai persamaam Regresi Linier Sederhana Kompetensi (X) terhadap Kinerja Pegawai (Y) dapat dilihat dari hasil pengolahan data menggunakan metode manual dengan rumus sebagai berikut:

$$
\begin{aligned}
\mathrm{a} & =\frac{\left(\sum Y\right)\left(\sum X^{2}\right)-\left(\sum X\right)\left(\sum X Y\right)}{n\left(\sum X^{2}\right)-\left(\sum X\right)^{2}} \\
& =\frac{(2256)(112180)-(2306)(109229)}{48(112180)-(2306)^{2}} \\
& =\frac{253078086-251882074}{5384640-5317636} \\
& =\frac{1196012}{67064} \\
& =17,85 \\
\mathrm{~b} & =\frac{n\left(\sum X Y\right)-\left(\sum X\right)\left(\sum Y\right)}{n\left(\sum X^{2}\right)-\left(\sum X\right)^{2}} \\
& =\frac{48(109229)-(2306)(2256)}{48(112180)-(2306)^{2}} \\
& =\frac{5242992-5202336}{5384640-5317636} \\
& =\frac{40656}{67004} \\
& =0,607
\end{aligned}
$$

Berdasarkan perhitungan diatas diperoleh koefisien persamaan regresi linier sederhana sebagai berikut:

\section{$\mathrm{Y}=\mathbf{1 7 , 8 5}+\mathbf{0 , 6 0 7 \mathrm { X }}$}

Penjelasan persamaan tersebut adalah sebagai berikut:

a. Konstanta sebesar 17,85 artinya jika kompetensi 0 maka tingkat Kinerja Pegawai nilainya sebesar 17,85 .

b. Koefisien regresi Kompetensi sebesar 0,607 bila kompetensi mengalami kenaikan satu satuan maka, Kinerja pegawai akan mengalami peningkatan sebesar 0,607 satuan dengan asumsi variabel bebas lainnya yang bernilai tetap.

\section{Uji Hipotesis}

Untuk mengetahui apakah Komunikasi Internal memiliki pengaruh dalam meningkatkan Kinerja Karyawan maka perlu dilakukan uji signifikansi dengan menggunakan rumus sebagai berikut: 
$t_{\text {hitung }}=\frac{r \sqrt{n-2}}{\sqrt{1-r^{2}}}$

Diketahui :

n: 48 , r: 0,7402

Jawab:

$t_{\text {hitung }}=\frac{0,7402 \sqrt{48-2}}{\sqrt{1-(0,7402)^{2}}}$

$t_{\text {hitung }}=\frac{0,7402 \sqrt{46}}{\sqrt{1-0,5479}}$

$t_{\text {hitung }}=\frac{0,7402(6,7823)}{\sqrt{0,451}}$

$t_{\text {hitung }}=\frac{5,0202}{0,6724}$

$t_{\text {hitung }}=7,4661$

$t_{\text {tabel }}:$ DK $=\mathrm{n}-2$

$\mathrm{DK}=48-2=46$

$t_{\text {tabel }}=2,013$

Dengan demikian, jika $t_{\text {hitung }}>t_{\text {tabel }}$, yaitu 7,4661 $>2,013$ yang artinya $\mathrm{H}_{\mathrm{a}}$ diterima dan

$\mathrm{H}_{\mathrm{o}}$ ditolak, berarti ada pengaruh yang signifikan antara kompetensi terhadap kinerja pegawai pada Biro Pembinaan Operasi Mabes Polri Jakarta.

\section{Pembahasan Penelitian}

Berdasarkan hasil penelitian ini menunjukkan bahwa terdapat pengaruh yang signifikan antara Kompetensi terhadap Kinerja Karyawan dengan nilai regresi $\mathrm{Y}=17,85+$ $0,685 \mathrm{X}$ yang artinya apabila setiap penambahan 1 (satu) poin variabel kompetensi maka akan meningkatkan kinerja sebesar 0,607 kali dengan kecepatan konstan. sebesar 17,85. Nilai koefisien korelasi sebesar 0,7402 artinya variabel kompetensi mempunyai tingkat hubungan yang kuat dengan variabel kinerja. Dari perhitungan Koefisien Determinasi (KD) diperoleh sebesar 0,5479, dapat disimpulkan bahwa kompetensi memberikan kontribusi terhadap kinerja pegawai sebesar $54,79 \%$ sedangkan sisanya sebesar $45,21 \%$ dipengaruhi oleh faktor lain yang tidak diteliti. Pengujian hipotesis dengan menggunakan uji statistik $t_{\text {hitung }}$ diperoleh $t_{\text {hitung }}>$ $t_{\text {tabel }}$ atau 7,461> 2,013 yang artinya $\mathrm{H}_{\mathrm{a}}$ diterima dan $\mathrm{H}_{\mathrm{o}}$ ditolak, artinya terdapat hubungan yang signifikan antara kompetensi dengan kinerja pegawai pada Biro Pengembangan Operasi Mabes Polri Jakarta.

\section{Kesimpulan}

Kompetensi kerja pada Biro Pembinaan Operasi Mabes Polri sudah baik dilihat dari hasil jawaban responden yang berjumlah 48 orang dengan 12 instrumen pernyataan, dengan hasil prosentase sangat setuju (SS) sebesar $42 \%$ dan yang menjawab setuju (S) sebesar 33\%. Hal ini dapat dilihat dari tabel 4.4. dimana jawaban responden tertinggi pada variabel kompetensi yaitu ada pada indikator pemahaman dengan jumlah responden yang menjawab sangat setuju (SS) sebanyak 31 orang dan indikator pengetahuan dengan jumlah responden yang menjawab setuju (S) sebanyak 25 orang. Kinerja pada Biro Pembinaan Operasi Mabes Polri sudah baik dilihat dari hasil jawaban responden yang berjumlah 48 orang dengan 12 instrumen pernyataan, dengan hasil prosentase yang menjawab sangat setuju (SS) sebesar 34\%, dan yang menjawab setuju (S) sebesar $40 \%$. Hal ini dapat dilihat dari tabel 4.5. dimana jawaban responden tertinggi pada variabel kinerja yaitu ada pada indikator pengawasan dengan jumlah responden yang menjawab sangat setuju (SS) sebanyak 25 orang dan indikator kualitas kerja dengan jumlah responden yang menjawab setuju (S) sebanyak 21 orang. Terdapat pengaruh positif antara Kompetensi terhadap kinerja pegawai pada Biro Pembinaan Operasi Mabes Polri dengan nilai regresi sebesar $\mathbf{Y}=\mathbf{1 7 , 8 5}+\mathbf{0 , 6 0 7 X}$ yang artinya apabila setiap penambahan 1 (satu) poin variabel kompetensi maka hal itu akan meningkatkan kinerja sebesar 0,607 kali dengan 
konstansta sebesar 17,85. Nilai koefisien korelasi sebesar 0,7402 artinya variabel Kompetensi mempunyai tingkat hubungan kuat terhadap variabel kinerja. Dari hasil perhitungan koefisien determinasi (KD) diperoleh sebesar 0,5479 maka dapat disimpulkan bahwa kompetensi berkontribusi terhadap kinerja pegawai sebesar 54,79\% sedangkan sisanya 45,21\% dipengaruhi oleh faktor lain yang tidak diteliti. Pengujian hipotesis menggunakan uji statistic $\mathrm{t}$ hitung diperoleh nilai $t_{\text {hitung }}>t_{\text {tabel }}$ atau 7,4661 $>2,013$ yang artinya $\mathrm{H}_{\mathrm{a}}$ diterima dan $\mathrm{H}_{\mathrm{o}}$ ditolak, berarti ada pengaruh yang signifikan antara kompetensi terhadap kinerja pegawai pada Biro Pembinaan Operasi Mabes Polri Jakarta.

\section{Daftar Pustaka}

Arikunto, Suharsimi. 2010. Prosedur Penelitian Suatu Pendekatan Praktek. Jakarta PT. Rineka Cipta.

. 2013. Prosedur Penelitian Suatu Pendekatan Praktek. Jakarta PT. Rineka Cipta.

Donni, Juni Priansa. 2017. “Manajemen Kinerja Kepegawaian”. Cetakan ke-1, CV Pustaka Setia, Bandung.

Kasmir. 2016. "Manajemen Sumber Daya Manusia Teori dan Praktik". Cetakan ke-1, PT Rajagrafindo, Jakarta.

Mangkunegara, Prabu Anwar A.A. 2015. Manajemen Sumber Daya Manusia Perusahaan. Bandung : PT. Remaja Rosdakarya.

Rivai, Veithzal. 2013. Manajemen Sumber Daya Manusia Untuk Perusahaan. Jakarta. Raja Grafindo Persada.

Sugiyono. 2014. Metode Penelitian Kuantitatif, Kualitatif dan $R \& D$. Bandung. Alfabeta . 2015. Metode Penelitian Dan Pengembangan, Edisi Pertama. Bandung Alfabeta. . 2016. Metode Penelitian Kuantitatif Kualitatif dan $R \&$ D. Bandung. Penerbit CV. Alfabeta.

Suharsimi Arikunto. 2013. Prosedur Penelitian Suatu Pendekatan Praktek. Jakarta. PT. Rineka Cipta

Arikunto, Suharsimi. 2010. Prosedur Penelitian Suatu Pendekatan Praktek. Jakarta PT. Rineka Cipta.

Wibowo. 2016. "Manajemen Kinerja". Edisi Kelima, Cetakan Ke-10, PT RajaGrafindo Persada, Jakarta. 